\title{
PRESERVICE INFORMATION TECHNOLOGY TEACHERS' INTERNET USAGE PROBLEMATIC: INTERNET INFORMATION POLLUTION
}

\author{
Adile Aşkım Kurt, Mehmet Firat \\ Anadolu University, Eskişehir, Turkey \\ E-mail: aakurt@anadolu.edu.tr, mfirat@anadolu.edu.tr
}

\begin{abstract}
The main purpose of this study is to determine the views of preservice teachers of Information Technologies and investigate the effect of information pollution on internet use. Semi-structured interview and questionnaire methods were used in this mixed methods study. 12 preservice teachers participated in the interview part and $674^{\text {th }}, 3^{\text {rd }}$ and $2^{\text {nd }}$ course students participated in the questionnaire on voluntary basis, from Computer Education and Instructional Technologies Department. As a result of the analysis of the data obtained, it was found out that the preservice teachers consider information pollution unnecessary, incorrect and out-of-date information found disorganized in an environment; the preservice teachers regard the most important factor causing information pollution on the internet is the fact that everybody can write about anything. Also preservice teachers denoted that the most important effect of internet information pollution is waste of time.
\end{abstract}

Key words: Internet, information access, information overload, information pollution.

\section{Introduction}

In recent years, there have been great developments in computer systems and information services. These technological innovations can now be seen in almost every field and have begun to influence today's society in various aspects. Mobile phones, micro computers and the internet are among such technological developments based on computer and information systems. In a broader sense, it could be said that with the use of the internet, which is defined as a network system of non-central links that surround the whole world (Sekin, 2007), it is possible to retrieve any information from anywhere in the world. With the rapid development of the network technologies, internet has become the most popular communication tools which allow users to access different information from all over the world (Zhang, Fang \& Wang, 2004). It was more difficult to retrieve information only a decade ago, one can now use search engines to retrieve millions of data-bases in just a few seconds.

Information overload has become an important term with its effects on the society since information is in a constant movement due to technological developments and inventions. The whole world has benefitted from the increase in information in the processes of both transition from agricultural society to the industrial society and transition from industrial society to the information society. Similarly, technological devices that play an important role in the establishment of the information society have accelerated the increase in information. However, while the industry has made good use of the increase in information, insufficient attention has 
been paid to the potential risks of this increase in information (Prabhaker, 2004). It could be

stated that information that increase in an uncontrolled way has led to information pollution, one of the important problems of today's society. Geisler, Prabhaker and Nayar, (2003) discussed the process of the occurrence of information pollution in terms of social change and emphasized the necessity to increase the awareness of information pollution, to solve the problems one by one and to provide unity in information management so that information pollution could be prevented.

The internet, supported with wide band and big data-bases, is also used for the storage of an unlimited amount of information. Today, individuals and organizations can provide large amounts of information at low cost by using internet. This advance is seductive and can cause people to forget some communication fundamentals, such as understanding intended audiences and how they seek, asses and use information (Nelson, 2007).

When the information access system (www) established the accessible Web in 1990s, email and the net became a fast and easy way of communication (Twist, 2003). It could technically be stated that information pollution on the internet occurs right at this point. Today's Web is so much bigger that it's impossible to organize it by category in a meaningful way (Kantor, 2007). Because of the rapid increase in the amount of information in internet environment, the disorder and out of control transfer of information lead to increase information pollution, and caused serious harm to society (Bing, 2009). According to Sönmez (2004), inactive and non-updated web-sites results in great information pollution on internet. These web-sites that unnecessarily take users' time also causes a significant loss of money paid to the servers. Similarly, the excessive amount of words and unnecessary details found on the internet prevent individuals from retrieving useful information. Hence, due to the information pollution that increasingly pollutes our information environment, the information that we need is lost in the mass of irrelevant information (Nielsen, 2003). Because we ignored the importance and quality of the data collected, we generated our data quality indicators with different assumptions representing common data pollutions (Berti-Equille, 2007). In this respect, the data of hundreds of terra-bytes found on the internet for various purposes increase the amount of the accessible information. This situation could be said to make it difficult to retrieve correct, consistent and reliable information. In other words, the user who wants to find information about a certain subject is most often likely to retrieve incorrect, unreliable or irrelevant information. Therefore, since the accessible information does not show a sign of unity, information pollution on the internet reveals the issues of accuracy, consistency and reliability (Prabhaker, 2004).

Nielsen (2003), giving different examples for information pollution, emphasizes that individuals have difficulty in finding the necessary information due to the over-use of words in certain environments and that the internet is at the top of such environments. In this respect, Nielsen (2004), in Table 1, reports what individuals and institutions should do to decrease information pollution on the internet.

Table 1. Ten steps for cleaning up information pollution.

\begin{tabular}{|l|l|}
\hline \multicolumn{1}{|c|}{ What Individuals Can Do } & \multicolumn{1}{c|}{ What Companies Can Do } \\
\hline 1. Create a special e-mail address & 7. Don't circulate internal e-mail to all employees \\
2. Don't check your e-mail all the time & 8. Answer common customer questions on your website using \\
3. Don't use "reply to all" & clear and concise language \\
$\begin{array}{l}\text { 4. Write short } \\
\text { 5. Write informative subject lines }\end{array}$ & $\begin{array}{l}\text { 9. User test your intranet } \\
\text { 6. Avoid IM (instant messaging) }\end{array}$ \\
\hline
\end{tabular}


PROBLEMS

OF EDUCATION

IN THE $21^{\text {st }}$ CENTURY

Volume 41, 2012

30

In their study, Cai \& Zhang (1996) state that information pollution is a pile of widespread yet unwanted messages and that one day, these messages could deeply influence the social life bearing negative results. In their study, the researchers grouped a total of 897 e-mails under three categories as important, useful and useless and tried to measure the information pollution on the internet. It was concluded in the study that useless messages increase information pollution since they are a lot in number. In other work Anderson (2003) state that the general problem of information pollution on the internet should be seriously considered and a great care should be taken in attributing importance to information which cannot be checked. For instance, a material in an official web site may be reliable but great care should be taken for other forms of sources which cannot be validated.

The concept of information pollution on internet is a relatively new concept. So this concept is not adequately discussed in literature. In general, when looking to the explanations and definitions about the concept in literature, some components are emphasized like irregular and uncontrolled transfer of information, wrong information and have lost their effectiveness, unnecessary, filthy information, information broadcast of noise, unwanted messages, invalidated information, inactive and non-updated web-sites dimensions (Cai \& Zhang, 1996; Fenggang, 1999; Nielsen, 2003; Anderson, 2003; Mei, 2003; Sönmez, 2004; Prabhaker, 2004; Bing, 2009). However, it is not possible to mention a common definition, which determines the scope of the concept of information pollution on the internet.

Today, teachers increasingly use internet and other computer-based educational tools in their classes, and they encourage their students to use such tools as well. Students, who need to retrieve information quickly, use internet to do their in-class or out-of-class homework, to get information about a subject and to prepare for an exam. Thanks to the developing technology and communication, students can now retrieve a lot of information in a very short time and improve their learning environment (Pines \& West, 1986).

Students, who can easily retrieve any kind of information via the internet, can be said to experience various difficulties like the information pollution on the internet while finding the necessary information among all the information they have retrieved. Since information is not stored in regular categories on the internet and since information from various sources is in the same environment, the difficulties that students face are doubled. Students either retrieve incorrect information or waste their time on scientifically worthless or irrelevant subjects. Sometimes, they even forget about their search, start to focus on another subject and lose their interest in the previous subject. This necessitates guidance for students to retrieve correct, reliable and up-to-date information quickly. It is our directors and teachers who have the primary responsibility to lead and guide our children and youth so that they can retrieve the useful and necessary information (EGITEK, 2004). It could be stated that especially IT teachers have the biggest role in helping students retrieve correct, reliable and up-to-date information in the internet environment. In this respect, it will be useful for the improvement of the process if the views of preservice teachers of IT are determined. In this way, information pollution on the internet will effectively be evaluated with the views and suggestions of preservice teachers attending the Computer Education \& Instructional Technologies Department (CEITD).

In this respect, the purpose of this study is to examine the views and participations of preservice teachers from the CEITD about information pollution on the internet. In line with this general purpose, the research questions are as follows: What are the views and participations of preservice teacher attending the CEITD about;

1. the concept of information pollution,

2. the environments that include information pollution,

3. the factors that lead to information pollution on the internet,

4. decreasing information pollution on the internet,

5. the effects of information pollution on internet use in respect to gender and class? 


\section{Methodology of Research}

PROBLEMS

OF EDUCATION

IN THE $21^{\text {st }}$ CENTURY

Volume 41, 2012

31

In this mixed methods study semi-structured interview and questionnaire techniques was used. Consisting of eight item questionnaire was developed by researchers to verify the result from interview about the effects of information pollution.

\section{Sample}

12 preservice teachers from CEITD (six of the participants were female and six were male) participated in interview. The real names of the participants were not used due to privacy policies. Therefore, they were called with their code names. For the quantitative part of the study $674^{\text {th }}, 3^{\text {rd }}$ and $2^{\text {nd }}$ course students participated in the questionnaire on voluntary basis, from CEITD in Faculty of Education at Anadolu University. The demographic characteristics of the 67 students participating in questionnaire can be seen in Table 2 below.

\section{Table 2. Demographic characteristics of participants.}

\begin{tabular}{|c|c|c|}
\hline & Frequency (f) & Percentage (\%) \\
\hline \multicolumn{3}{|l|}{ Gender } \\
\hline Female & 15 & 22.38 \\
\hline Male & 52 & 77.62 \\
\hline \multicolumn{3}{|l|}{ Course } \\
\hline $2^{\text {nd }}$ Course & 25 & 37.3 \\
\hline $3^{\text {rd }}$ Course & 32 & 47.7 \\
\hline $4^{\text {th }}$ Course & 10 & 15 \\
\hline
\end{tabular}

Instruments and Procedure

The researchers prepared semi-structured interview and Likert type questionnaire forms appropriate to the purpose of the study, and four field-experts (two were in qualitative research, two were in educational technology) were consulted for the validity of the forms prepared. In line with the suggestions of the experts, the interview and questionnaire forms was finalized and made ready for application.

The questionnaire was used only for the fourth research question. First, a question pool created by researchers based on interview related to the affects of internet information pollution. In line with the suggestions of the experts, eight questions selected and revised from 14 questions. Questionnaire applied after the interview.

The interviews were held in the places and at the times agreed by each participant. At the beginning of the interviews, the participants were orally asked for permission for the interview, which was also taken in written previously. The questions in the interview form were directed to each preservice teacher, and their responses were audio-recorded. After the audio-records were transcribed on a computer, for the reliability of the data, two people from the field independently listened to three randomly-chosen audio-records and read their transcriptions.

\section{Statistical Analysis}

Qualitative data collected from interview were analyzed through the inductive analysis. For this purpose, the data were examined by the researchers, divided into meaningful parts and coded. The data coded were gathered and categorized. The themes were determined and transferred into an interview coding key. For the reliability of the data obtained, two experts with knowledge of the field and of qualitative research were asked for their views. The markings 
of the researchers and of the experts were compared. By using the formula of [agreement / (disagreement + agreement) $]^{*} 100$ (Miles \& Huberman, 1994), the reliability of the study was calculated as $86 \%$. The value exceeding $80 \%$ was concluded as to prove the reliability of the study. The data obtained were supported with direct quotations from the raw data obtained via the interviews. As a result, the findings were revealed. For the analysis of the quantitative data, the software of SPSS 17.0 was used.

\section{Results of Research}

In order to reveal the common view while transferring the findings obtained as a result of the responses given by the preservice teachers to the interview questions, examples were given for the sub-themes and themes with high frequencies. According to the data obtained, the research findings were gathered under five main themes as; concept of information pollution, information-polluted environment, the factors that cause information pollution on the internet, the effects of information pollution on internet use, decreasing information pollution on the internet.

\section{Concept of Information Pollution}

Preservice IT teachers stated several views about the concept of information pollution, yet six of the participants defined information pollution as information overload. Deniz, stated his view as "to me, information pollution is rather a large amount of information that we want to retrieve. That is, there is so much information that we don't know which information is right, or which is wrong." Another preservice teacher Ayla defined information pollution as "... a big deal of information, right or wrong, useful or useless, relevant or irrelevant."

Five of the preservice teacher stated that information pollution is the wrong information. Aylin reported that information pollution is "generally the wrong information...." Five of the preservice teachers stated that unnecessary information is the information pollution. Batu, a preservice teacher, stated that "...information pollution is the pile of a big amount of information, necessary or unnecessary. Inexpert people gather such information and end up with a confusing and disorganized environment...."

Five of the preservice teachers consider information pollution as non-updated information. For example, Sanem, stated her view about information pollution as "...information which is not so much reliable and which is not updated...."

Besides these, preservice teachers defined information pollution as inconsistent information (2), unreliable information (1), information sent by inexpert people (1), information for business purposes (1), and as information found disorganized in an environment (1).

\section{Information Polluted Environments}

IT preservice teachers stated various views about the environments where information pollution is found. All of the preservice teachers reported that there is information pollution in the internet environment, while five of them emphasized that information pollution especially exists in the internet environment. Fatma, one of the preservice teachers, stated that "it is certainly the internet environment. Subjects irrelevant to each other are found in the internet environment, or the same information could be interpreted in different ways in different websites. It is certainly the internet environment." Another preservice teacher, Yunus, reported that "I mostly come up with information pollution mostly on the internet."

Preservice teachers consider television as the biggest environment for information pollution besides the internet. Regarding this point, Ayla stated that "...there is everything, 
right or wrong, on television...," while Fatma reported that "it is found on television, too. For

example, while you watch some news in one television channel with certain comments, you watch the same news in another channel with different comments."

Four of the preservice teachers regard newspapers as an information-polluted environment. For instance, Yalın, mentions that "...groundless news found in newspapers lead to information pollution." In addition to these, the preservice teachers consider libraries (2), magazines (1), family (1), streets (1), and the mass media (1) as information-polluted environments.

\section{Factors that Cause Information Pollution on the Internet}

The preservice teachers expressed various views about the factors that cause information pollution on the internet. As seen in Table 2 according to five of the preservice teachers, the fact that everybody can write about anything on the internet is among the factors that lead to information pollution on the internet. Sercan, a preservice teacher, stated that "....apparently, the internet is a clear source. That is, people can use it freely. Almost in the whole world, for example, there is no limitation to the use of the internet. Well, everybody can submit anything they want. There is no interference, so we can say that the internet is an environment that includes the most disorganized information. The most crowded place. It is even like a rubbish dump. Any information about anything. There is no organization...."

Table 3. Factors that cause information pollution on internet to the preservice teachers.

\begin{tabular}{|l|c|}
\hline \multicolumn{1}{|c|}{ Factors } & Frequency \\
\hline Everybody can write about anything & 5 \\
\hline Incorrect information & 5 \\
\hline Information which is not controlled by experts & 4 \\
\hline Using Web sites for commercial purpose & 4 \\
\hline Any kind of disorganized information found together & 3 \\
\hline Information that are not updated & 3 \\
\hline Repetition of the same information & 2 \\
\hline Use of information by a number of people & 1 \\
\hline A large amount of information & 1 \\
\hline Unreliable information & 1 \\
\hline Information without any reference & 1 \\
\hline Business concerns & 1 \\
\hline Too many e-mails & 1 \\
\hline The internet itself as an open source & 1 \\
\hline
\end{tabular}

Five of the preservice teachers reported that incorrect information found on the internet is a factor that leads to information pollution on the internet. One of the preservice teachers, Yalın, stated that "...incorrect information, information without any reference, inconsistent information, and information that anybody can submit without control. That is, everybody can send any information in any way they want, and such information is considered to be correct. What else, the submission dates of information are mostly unknown. Thus, we don't know whether the information is up-to-date or not. Incorrect information, incomplete information, inconsistent information, unreliable information."

Four of the preservice teachers reported another factor to be the information which is 
PROBLEMS

OF EDUCATION

IN THE $21^{\text {st }}$ CENTURY

Volume 41, 2012

34

not controlled by experts. Nihal, stated that "the basic factors ...everybody has the right to write about anything they want. That is, people tend to look intellectual; well there is a saying about that: If you know it, tell it, then they'll think you are an intellectual. It is the same for the internet in Turkey. Most of the information on the internet is unnecessary for me. It is not totally controlled; a pile of uncontrolled information. This is the biggest factor for information pollution."

Fatma, one of the preservice teachers, emphasized that "there is inconsistent and incorrect information. The institutions are not impartial ... As I said, incorrect information is gathered. When everybody believes that they themselves are right, naturally, you cannot discriminate between the wrong and the right."

Furthermore, among the factors that cause information pollution on the internet are using Web sites for commercial purpose, any kind of disorganized information found together, information that are not updated, repetition of the same information, use of information by a number of people, a large amount of information, unreliable information, information without any reference, business concerns, too many e-mails, and the internet itself as an open source.

\section{Effects of Information Pollution on Internet Use}

When the views of the preservice teachers of IT about the effects of information pollution on internet use are examined, it is seen that almost all the preservice teachers believe that information pollution influences internet use. However, one preservice teacher reported that it does not any effects on internet use. Sanem, a preservice teacher who believed information pollution affects internet use, stated that “...I don't think it influences internet use so much. Well, I believe it is in the user's hand...."

Six of the preservice teachers who believe that information pollution influences internet use reported that this leads to a waste of time. Aylin, a preservice teacher, stated that "time... we have a time problem. In fact, it is a half-an-hour job, yet it sometimes takes a whole day to retrieve the information we need. Sometimes, we can't find the information, and we go to the library. Yes, it certainly causes a time problem. Most of the time, we have to examine all the pages on the internet. Another preservice teacher Fatma reported that ".....because you can't easily retrieve the information all the time. Sometimes, it is a loss of time."

Five of the preservice teachers stated that information pollution on the internet causes them to search the information from other sources. Ayla, a preservice teacher, found library more reliable than the internet stating that "In the past, I used the internet more for research purposes. Later, when I realized that most of the time, I found incorrect information, I began to go to the library of our university. I sometimes use the internet to search for the necessary information at least as main headings. And when I go to the library, I search for details. I find it better to go to the library."

Four of the preservice teachers reported that they felt themselves in conflict. For example, Sercan felt suspicious about the correctness of the information he found on the internet: "for example, you skip the most appropriate information without getting the exact information. Sometimes, that is the case. For example, you keep searching, but you can't find it. All the time you end up with different things. That is, you feel desperate since you can't find the information you need. Alas! I couldn't find it. I can't retrieve the correct information. I wonder if this information is right or wrong, updated or not."

In addition to these, the preservice teachers reported that information pollution decreases motivation and thus decreases their internet use; that they get lost among incorrect information; they lose their hope to find the correct information; and that they, for all these reasons, do not want to use the internet, which results in loss of money.

In order to verify the views of IT preservice teachers about effects of information 
Adile Aşkım KURT, Mehmet FIRAT. Preservice Information Technology Teachers' Internet Usage Problematic: Internet Information Pollution

pollution on internet users, questionnaire applied to 67 IT preservice teachers. For the analysis of the questionnaire data regarding the affects of internet information pollution on the internet use of IT students, descriptive statistics were used. The numbers and means $(\overline{\mathrm{X}})$ are presented in Table 4 below.

Table 4. Affects of internet information pollution on the internet use of IT students.

\begin{tabular}{|l|c|c|}
\hline \multicolumn{1}{|c|}{ Affects } & N & $\bar{X}$ \\
\hline I find myself reviewing other issues. & 67 & 3.34 \\
\hline I spend too much time. & 67 & 3.38 \\
\hline I'm getting tired. & 67 & 3.03 \\
\hline I'm losing my focus. & 67 & 3.13 \\
\hline My search motivation decreases. & 67 & 3.18 \\
\hline I forget what I was looking for. & 67 & 2.27 \\
\hline I feel lost. & 67 & 2.40 \\
\hline I feel helpless. & 67 & 2.27 \\
\hline
\end{tabular}

As seen in Table 4 the mean of affects of internet information pollution rated by students are close. However, responses can be divided into two groups (first 5 item and last 3 item) by looking at means of 8 item. According to the answers given to the questionnaire the most highlighted effect of internet information pollution on the internet use is spending too much time.

Firstly Kolmogorow-Smirnow normality test conducted to determine whether the frequencies of IT students about affects of internet information pollution had a normal distribution or not. The results are presented in Table 5 below.

Table 5. Kolmogorov-Smirnov normality test results.

\begin{tabular}{|l|l|l|l|l|}
\hline & $\mathbf{N}$ & $\overline{\mathbf{X}}$ & \multicolumn{1}{|c|}{ Kolmogorov-Smirnov Z } & $\mathbf{p}$ (2 tailed) \\
\hline Internet information pollution effects & 67 & 2.8769 & 0.864 & 0.444 \\
\hline
\end{tabular}

According to the Kolmogorov-Smirnov test results, the scores related to the IT students' replaces on effects of internet information pollution had a normal distribution $\left[\mathrm{D}_{(67)}=0.864\right.$, $\mathrm{p}=0.444>0.05]$. This finding revealed that the parametric tests can be applied to the scores of IT students about affects of internet information pollution.

In order to investigate the affects of information pollution to IT students with respect to gender, independent samples t-test was applied. As a result of the independent samples t-test, there was no significant difference between the degrees of IT students' agreement with internet information pollution effects with respect to their gender $\left[\mathrm{T}_{(65)}=0.073, \mathrm{p}=0.94>0.05\right]$. In order to investigate the effects of information pollution to IT students with respect to class, one way ANOVA was applied. 
PROBLEMS OF EDUCATION IN THE $21^{\text {st }}$ CENTURY Volume 41, 2012

Table 6. One way ANOVA results.

\begin{tabular}{|l|l|c|c|c|c|}
\hline Affects of internet information pollution & & df & MS & F & p \\
\hline \multirow{3}{*}{ I find myself reviewing other issues } & Between Groups & 2 & 0.065 & 0.04 & 0.957 \\
\hline & Within Groups & 64 & 1.484 & & \\
\hline & Total & 66 & & & \\
\hline \multirow{4}{*}{ I spend too much time } & Between Groups & 2 & 5.326 & 4.30 & $0.018^{*}$ \\
\hline & Within Groups & 64 & 1.238 & & \\
\hline & Total & 66 & & & \\
\hline \multirow{4}{*}{ I'm getting tired } & Between Groups & 2 & 1.681 & 0.99 & 0.377 \\
\hline & Within Groups & 64 & 1.697 & & \\
\hline & Total & 66 & & & \\
\hline \multirow{3}{*}{ I'm losing my focus } & Between Groups & 2 & 1.291 & 1.09 & 0.340 \\
\hline & Within Groups & 64 & 1.175 & & \\
\hline & Total & 66 & & & \\
\hline \multirow{3}{*}{ My search motivation decreases } & Between Groups & 2 & 7.355 & 5.40 & 0.007 \\
\hline & Within Groups & 64 & 1.362 & & \\
\hline & Total & 66 & & & \\
\hline \multirow{3}{*}{ I forget what I was looking for } & Between Groups & 2 & 1.293 & 0.93 & 0.398 \\
\hline & Within Groups & 64 & 1.384 & & \\
\hline & Total & 66 & & & \\
\hline \multirow{3}{*}{ I feel lost } & Between Groups & 2 & 2.242 & 1.56 & 0.217 \\
\hline & Within Groups & 64 & 1.432 & & \\
\hline & Total & 66 & & & \\
\hline \multirow{3}{*}{ I feel helpless } & Between Groups & 2 & 4.512 & 3.00 & 0.057 \\
\hline & Within Groups & 64 & 1.502 & & \\
\hline & Total & 66 & & & \\
\hline
\end{tabular}

As can be seen in Table 7, a significant difference was found between the degrees of IT students" agreement with "I spend too much time" and "My search motivation decreases" respect to their classes. For the purpose of determining which groups caused this difference, Tukey HSD test. The Tukey HSD test results are presented in Table 7 below.

\section{Table 7. Tukey HSD test results.}

\begin{tabular}{|c|c|c|c|c|c|}
\hline \multirow[t]{3}{*}{ Dependent Variables } & (l) Class & (J) Class & MD (I-J) & SE & $p$ \\
\hline & 2 class & 3 class & 0.31375 & 0.29705 & 0.545 \\
\hline & & 4 class & $1.22000\left(^{*}\right)$ & 0.41639 & 0.013 \\
\hline \multirow[t]{4}{*}{ I spend too much time } & 3 class & 2 class & -0.31375 & 0.29705 & 0.545 \\
\hline & & 4 class & 0.90625 & 0.40317 & 0.071 \\
\hline & 4 class & 2 class & $-1.22000\left(^{*}\right)$ & 0.41639 & 0.013 \\
\hline & & 3 class & -0.90625 & 0.40317 & 0.071 \\
\hline \multirow{6}{*}{ My search motivation decreases } & 2 class & 3 class & 0.27000 & 0.31147 & 0.663 \\
\hline & & 4 class & $1.42000\left(^{*}\right)$ & 0.43660 & 0.005 \\
\hline & 3 class & 2 class & -0.27000 & 0.31147 & 0.663 \\
\hline & & 4 class & $1.15000\left(^{*}\right)$ & 0.42274 & 0.023 \\
\hline & 4 class & 2 class & $-1.42000\left(^{*}\right)$ & 0.43660 & 0.005 \\
\hline & & 3 class & $-1.15000\left(^{*}\right)$ & 0.42274 & 0.023 \\
\hline
\end{tabular}


As can be seen in Table 7, regarding the degrees of IT students' agreement with the "I spend too much time" internet information pollution effect, there was a significant difference between the $2^{\text {nd }}$ and $4^{\text {th }}$ classes at the level of $p=0.013$. According to this result $2^{\text {nd }}$ class students spend more time than $4^{\text {th }}$ class students because of the internet information pollution. Regarding the degrees of IT students' agreement with the "My search request decreases" internet information pollution effect, there was a significant difference between the $2^{\text {nd }}$ and $4^{\text {th }}$ classes at the level of $p=0.005$, between the $3^{\text {rd }}$ and $4^{\text {th }}$ classes at the level of $p=0.023$. According to this result motivation of $2^{\text {nd }}$ and $3^{\text {rd }}$ class students more decrease than $4^{\text {th }}$ class students because of the internet information pollution.

\section{Views and Suggestions about Decreasing Information Pollution on the Internet}

According to the views of the preservice teachers about decreasing information pollution on the internet, two of the preservice teachers stated that they do not believe information pollution on the internet can be decreased; on the other hand, ten of them reported that information pollution could be decreased yet added that this is very difficult to do so, though it could be partly achieved.

Ayla, a preservice teacher who believes that information pollution on the internet can be decreased despite its difficult process, stated that "...In fact, this is very difficult because, for example, while authoring a book, experts check it. They correct the mistakes. They check it, say, for any spelling or punctuation mistakes, or like that. But there is a constant entry of data on the internet...." It could be stated that one of the reasons why it is difficult to decrease information pollution on the internet is that there is a constant entry of data on the internet.

As for the suggestions of the preservice teachers about decreasing information pollution on the internet, they recommend that information submitted on the internet be controlled (6); and that people sharing information become conscious (5). Batu, a preservice teacher, expressed his views about decreasing information pollution on the internet, stating that "a structure like a control-board can be established, in fact, to prevent this."

Sanem, another preservice teacher emphasized that people sharing information should become more conscious and added that "people should become more conscious; that is, the people who use the internet. Families will become conscious, and students, too; or the families of the teachers will the responsibility to make students more conscious...." Similarly, Sercan stated that "people sharing information should be more careful, more selective and share the correct information."

Besides these two suggestions emphasized by most of the preservice teachers, the preservice teachers put forward a number of different suggestions. These are; information should be submitted to the web sites of educational institutions to inform users; information should be categorized; one web site should focus on only a single subject; the web sites that present information should not have any other concerns; web pages prepared for business purposes should be prevented; e-books should be emphasized more; the web sites should be updated; the web sites that are not used should be removed; unnecessary information should be deleted; and e-mails should not be spread out more than necessary. It could be stated that such suggestions of the preservice teachers will contribute to decreasing information pollution on the internet.

\section{Discussion}

When the codes that form the theme of the views of preservice IT teachers about the concept of information pollution are examined, it is seen that preservice teachers regard information pollution as "information overload", "unnecessary information", "incorrect information" and "non-updated information" which is found disorganized in an environment. In this respect it is 
possible to visualize internet information pollution in context of broken balance of information in internet environment as shown below.
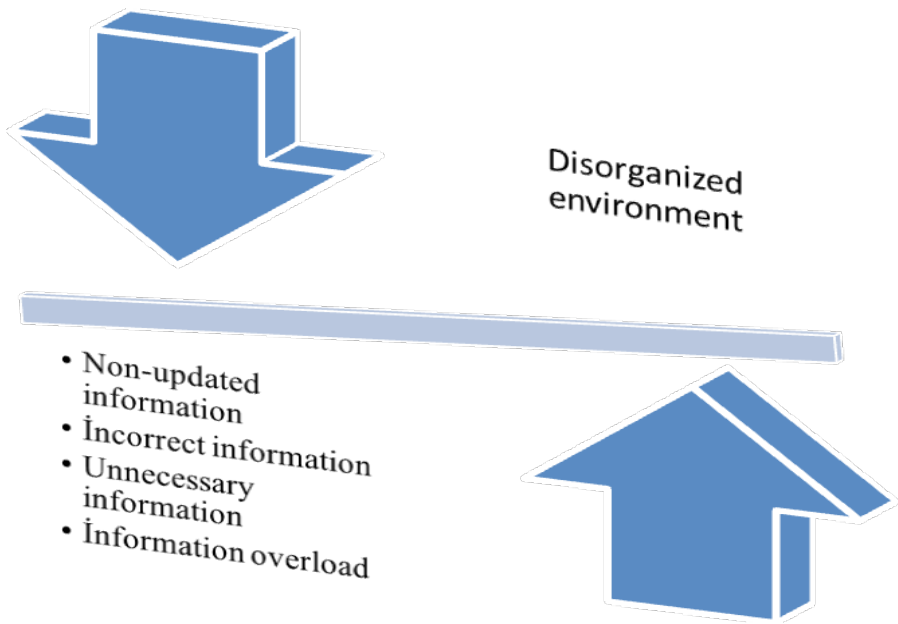

\section{Figure 1: Concept of internet information pollution.}

When the codes that form the theme of the views about information-polluted environments were examined, it was seen that preservice teachers consider the internet as the most information-polluted environment. This finding of the study is consistent with Nielsen's (2003) claim that "in certain environments, over-use of words makes it difficult for people to retrieve useful information, and at the top of such environments comes the internet". One reason for this might the fact that preservice teachers are in a constant interaction with the internet due to their profession. It could further be stated that information pollution has become an important problem in the internet environment. This finding is also parallel to Nielsen's (2004) conclusion that "due to information pollution, what we should know is found scattered among piles of irrelevant information." Moreover, since preservice teachers also regard the television and newspapers as information-polluted environments, it is clear that people should become conscious of the mass media.

According to the preservice teachers, the most important factor that causes information pollution on the internet is that everybody can write about everything since the internet is an open source and that there is incorrect information. This finding revealed in the study is consistent with the belief of Sönmez (2004) that non-updated and inactive web sites lead to great information pollution on the internet. Moreover, according to the preservice teachers, among the most important factors that cause information pollution on the internet is the fact that information is not controlled by experts and that every kind of information is found disorganized on the internet. This finding is consistent with belief of Hamid (2002) that because of the information overload on internet it is a great need to create order from chaos so that information can be used effectively. Hence, in order to decrease information pollution on the internet, technically, there should be a control mechanism and/or individuals should be trained on information sharing. In her study, Chase (2008) emphasized that experienced individuals should be actively involved in the operation of information systems or technical infrastructures supporting information systems.

When the responses given by the preservice teachers are examined, it is seen that information pollution on the internet is a loss of time for them; that they use other sources to search the information they need; and that such problems influences their internet use in a negative way as seen in Figure 2. 


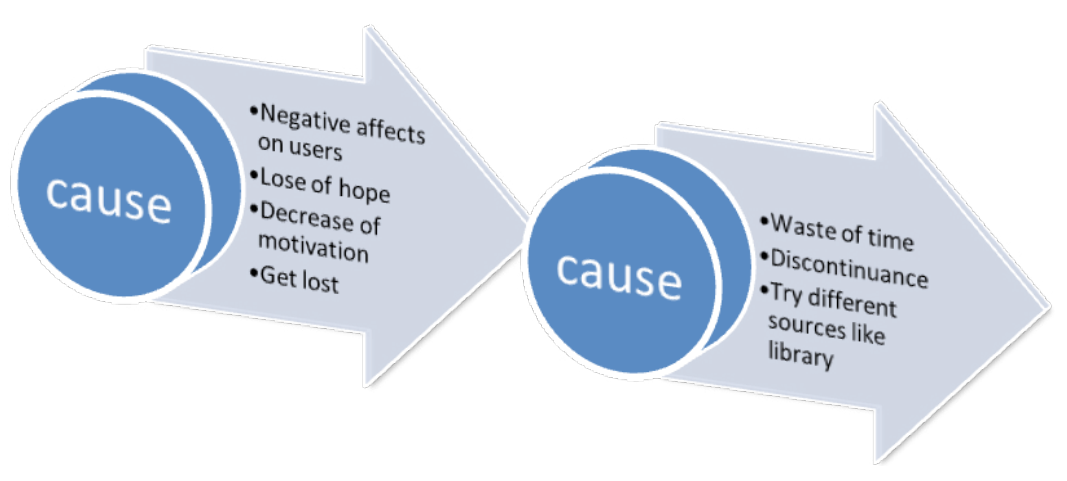

\section{Figure 2: Effects of internet information pollution.}

Based on the results, it can be said that IT students from lower classes were more affected from internet information pollution. In other words, inexperienced IT preservice teachers more affected from internet information pollution. In this respect different activities providing awareness related to internet information pollution can be useful for lower classes. Beside this informative meetings carried out related to search strategies in internet. According to Kabakç1, Firat, İzmirli and Kuzu, (2010) pre-service preservice teachers' skills and competencies about internet search strategies should be supported by related courses and /or contents.

\section{Conclusions and Suggestions}

When the views of 12 IT preservice teachers about what information pollution is are all considered together, it is possible to reach a common definition. Based on this common definition concluded from the views of the preservice teachers, information pollution occur when a big amount of unnecessary, incorrect, non-updated, unreliable, inconsistent and commercial information is found disorganized in the internet environment. Moreover, within the concept of information pollution, the preservice teachers draw the attention to the information submitted without any expert control.

According to the preservice teachers, information pollution especially exists in the internet environment. All of the preservice teachers reported that there is information pollution in the internet environment, while five of them emphasized that information pollution especially exists in the internet environment. Furthermore, preservice teachers consider television as the biggest environment for information pollution besides the internet. Among the problems experienced by the preservice teachers due to information pollution on the internet were "retrieving irrelevant information", "hesitating about the correctness of the information" and "retrieving a very large amount of information."

According to the preservice teachers, among the most important factors that cause information pollution on the internet are; the internet is an open environment that everybody can use; there is incorrect information; web sites are used for business purposes; any kind of information is gathered together and found disorganized; and information on the internet is not updated. Additionally, most of the preservice teachers stated that information pollution on the internet influence internet use in a negative way. The preservice teachers believe that internet use is negatively affected due to such factors as wasting time, using other information sources, giving up searching for the necessary information, hesitating about the correctness of the information, and as experiencing decrease in motivation. Today, we use information and communication technologies even in our daily lives, so it is an important point that information pollution has negative effects on the use of these information sources.

Affects of internet information pollution on the students was investigated by a 
PROBLEMS

OF EDUCATION

IN THE $21^{\text {st }}$ CENTURY

Volume 41, 2012

40

questionnaire. In order to investigate the affects of information pollution to IT students with respect to gender, independent samples t-test, with respect to class, one way ANOVA was applied. According to the results from independent samples t-test, there is no significant difference with respect to their gender. But according the results from ANOVA IT preservice teachers from lower classes were more affected from internet information pollution especially in "spend too much time" and "search motivation decrease".

About decreasing information pollution on the internet, most of the preservice teachers stated that information pollution can be decreased in the internet environment and added that despite its difficult process, information pollution could partly be decreased. The preservice teachers believed the underlying reason for such a problem is that the internet is an environment open to everybody.

Among the most frequently mentioned suggestions of the preservice teachers about decreasing information pollution on the internet was the fact that information submitted to the internet environment be controlled and that people sharing information on the internet become conscious. In this respect, the preservice teachers hold the belief about sharing information via the internet that they themselves and all other users should be made conscious for a good training. Therefore in limitation of the study, it could be stated that a training to be given on information pollution on the internet will bear good results. Beside this to cope with information pollution, preservice teachers and teachers of information technologies could be trained about information search strategies and techniques via different courses and in-service training.

In the light of the findings revealed in the study, different studies can be conducted on the observation of the common effects of information pollution on internet use; the things that individuals and institutions can do to overcome information pollution; expert control over information sharing; and the effects of information pollution on internet use in education. On top of all this, minimization potential of new generation internet technologies like Web 2.0 and Web 3.0 tools could be investigated by several research designs in future studies.

\section{References}

Anderson, C.B. (2003). The internet: Tool of law, source of law or tool for Sources - Use of the Internet in legal practice using examples from international sales, Proceedings of 18th BILETA Conference: Controlling Information in the Online Environment, QMW, London.

Berti-Equille, L. (2007) Data quality awareness: a case study for cost-optimal association rule mining. Knowledge and Information Systems, 11(2), 191-215.

Bing, H. (2009). Summary of internet information pollution. Computer Development \& Applications, 7 , 7-26.

Cai, K. \& Zhang, C. (1996). Towards a research on information pollution, Proceedings of the IEEE International Conference on Systems, Man, and Cybernetics, 3124-3129.

Chase, N. (2008). An exploration of the culture of information technology: focus on unrelenting change. Journal of Information, Information Technology, and Organizations, 3, 135-150.

Fenggang, C. (1999). The forms and prevention of information pollution. Metallurgical Information Review, 5, 5-12.

Geisler, E., Prabhaker, P., \& Nayar, M. (2003). Information Integrity: An Emerging Field and State of Knowledge, Proceedings of the Portland International Conference in Management of Engineering and Technology, 217-221.

Hamid, A. A. (2002). E-Learning: Is it the "e" or the learning that matters? The Internet and Higher Education, 4, 311-316.

Kabakçı, E., Fırat, M., İzmirli, S., \& Kuzu, E.B. (2010). Opinions of Teachers on Using Internet Searching Strategies: An Elementary School Case in Turkey. Turkish Online Journal of Qualitative Inquiry, $1(1), 49-61$. 
Adile Aşkım KURT, Mehmet FIRAT. Preservice Information Technology Teachers' Internet Usage Problematic: Internet Information Pollution

PROBLEMS

OF EDUCATION

IN THE $21^{\text {st }}$ CENTURY

Volume 41, 2012

Kantor, A. (2007). Internet suffering from information overload. USA Today, Retrieved January 18, $2009 \mathrm{http} / /$ www.usatoday.com/tech/columnist/andrewkantor/2007-06-14-internet-organization N.htm.

Mei, L. J. (2003). The forms and prevention ways of information pollution in internet environment. Journal of Xinyang Teachers College, 3, 3-31.

Miles, M. B., \& Huberman, A. M. (1994). Qualitative Data Analysis, (2nd ed.), Thousand Oaks, CA: SAGE.

Nielsen, J. (2003). Information Pollution, Retrieved January 16, 2012 from http://www.useit.com/ alertbox/20030811.html

Nielsen, J. (2004). Ten Steps for Cleaning up Information Pollution, Retrieved January 8, 2012 from http://www.useit.com/alertbox/20040105.html

Nelson, D. E. (2007). Reducing information pollution in the Internet age. Preventing Chronic Disease: Public Health Research, Practice and Policy, 4 (1), 1-3.

Pines, A., \& West, L. (1986). Conceptual understanding and science learning: An interpretation of research within sources of knowledge framework. Science Education, 70 (5), 583-604.

Prabhaker, P. (2004). Information pollution: A disaster waiting to happen. Proceedings of Global Conference on Business \& Economics Annual Conference, UK: London.

Sekin, E. (2007). Internet, censorship and Education. Electrical Engineering, 430, 91-92.

Sönmez, B. (2004). Information refuse on the Internet. Retrieved February 2, 2011 from http://www. bendevar.com/v3/makale_176.html.

Twist, J. (2003). Web guru fights info pollution. BBC News Online Technology Reporter. Retrieved January 16, 2012 from http://news.bbc.co.uk/2/hi/technology/3171376.stm

Zhang, N., Fang, B., \& Wang, Y. (2004). Improving response capabilities to internet emergency through a high performance network resource platform. WSEAS Transactions on Information Science and Applications, 4 (1), 470-254.

Advised by Vincentas Lamanauskas, University of Siauliai, Lithuania

Received: January 29, 2012

Accepted: February 28, 2012

\begin{tabular}{|ll} 
Adile Aşkım Kurt & $\begin{array}{l}\text { Dr., Assistant Professor, Faculty of Education, Anadolu University, Eskişehir, } \\
\text { Turkey. } \\
\text { E-mail: aakurt@anadolu.edu.tr }\end{array}$ \\
\hline Mehmet Firat & $\begin{array}{l}\text { Resc. Assistant, Open Education Faculty, Anadolu University, Eskişehir, Turkey. } \\
\text { E-mail: mfirat@anadolu.edu.tr }\end{array}$
\end{tabular}

